\title{
O DESEMPENHO RECENTE DAS POLÍTICAS DE COMPRAS PÚBLICAS DA PRODUÇÃO DA AGRICULTURA FAMILIAR
}

\author{
Alexandre Valadares ${ }^{1}$ \\ Fabio Alves ${ }^{2}$ \\ Marcelo Galiza ${ }^{3}$ \\ Sandra Kitakawa Lima ${ }^{4}$
}

\section{APRESENTAÇÃO}

Desde meados da década de 1990, o conjunto de políticas públicas voltadas ao desenvolvimento rural no país passou a incorporar açóes específicas destinadas à agricultura familiar. Embora nunca tenham chegado a ocupar o centro da agenda de governo para o setor rural, essas açóes vêm desempenhando papel importante na estruturação produtiva dos agricultores familiares e na conformação de uma perspectiva de desenvolvimento rural alternativa à pauta econômica do agronegócio.

Na primeira fase, as políticas públicas voltadas à agricultura familiar reproduziam - em menor escala de recursos e com condiçóes diferenciadas de acesso - as grandes políticas de crédito agrícola (público e subsidiado), que, desde os anos 1970, têm sido a principal diretriz do apoio do Estado ao setor. A criação do Programa Nacional de Fortalecimento da Agricultura Familiar (Pronaf), em 1995, marca o início de uma política de crédito especificamente dirigida aos agricultores familiares, operada em paralelo aos planos safras que atendem à agricultura patronal.

No segundo momento, políticas públicas direcionadas ao atendimento de demandas mais específicas da agricultura familiar foram delineadas. Esse é o caso das políticas de compras públicas, formuladas com a dupla atribuição de incentivar a agricultura familiar, por meio da formaçáo de canais institucionais de apoio à comercialização, e de garantir assistência alimentar às populações em situação de risco, mediante a destinaçáo de alimentos da agricultura familiar a entidades da rede socioassistencial, a equipamentos públicos de segurança alimentar e nutricional, bem como a redes pública e filantrópica de ensino. Com esses objetivos fundamentais,

1. Técnico de planejamento e pesquisa na Diretoria de Estudos e Políticas Sociais (Disoc) do Ipea.

2. Especialista em políticas públicas e gestão governamental na Disoc/lpea.

3. Especialista em políticas públicas e gestão governamental na Disoc/lpea.

4. Pesquisadora do Subprograma de Pesquisa para o Desenvolvimento Nacional (PNPD) na Disoc/lpea. 
desde 2003 - ano de criação do Programa de Aquisição de Alimentos da Agricultura Familiar (PAA) - a compra pública da produção dos agricultores familiares passa a integrar a pauta das políticas públicas voltadas a esse setor (Brasil, 2003).

Ao longo dos anos 2000, o PAA conquistou posição central na estratégica de fomento à agricultura familiar. Mais que representar uma complementação à política de créditos - ao abrir um mercado institucional aos pequenos produtores e ampliar sua autonomia em relaçáo aos atravessadores -, mostrou-se importante vetor de estruturação produtiva das famílias rurais, tornando-se referência internacional de política pública brasileira bem-sucedida. A promessa de compra, a sustentação de preços, a destinação dos produtos a entidades socioassistenciais, o estímulo à diversificação de gêneros alimentícios e a promoção do associativismo como condição de escala para a comercialização vêm contribuindo tanto para a garantia de renda e segurança a alimentar das famílias como para, em sentido mais amplo, a organização dos produtores e a dinamização de circuitos mais regionalizados de produção e consumo de alimentos. Em outras palavras, de um lado, o programa passou a ser importante instrumento da política agrícola e, de outro lado, da política de segurança alimentar do país.

Dando continuidade à estratégia inaugurada pelo PAA, a Lei no 11.947/2009 abriu uma nova frente de compra pública da produção da agricultura familiar ao estabelecer que, no mínimo, 30\% do valor repassado pelo Fundo Nacional de Desenvolvimento da Educação (FNDE) a estados e municípios para o Programa Nacional de Alimentaçáo Escolar (PNAE) deveriam ser usados na compra de alimentos de produtores familiares (Brasil, 2009). Alternativa local ao abastecimento alimentar das escolas - que, em muitos casos, recebiam os produtos de fornecedores de outros municípios ou estados e com grande percentual de processados na cesta de alimentos -, o PNAE também promoveu importante estímulo aos circuitos curtos de comercialização, permitindo que mais alimentos in natura viessem compor a provisão regular da merenda nos estabelecimentos de ensino.

Apesar das virtudes e das avaliaçóes favoráveis que as políticas de compra pública da produção agrofamiliar apresentaram, os quinze anos de experiência não foram suficientes para ampliar significativamente suas escalas, que atingiram um público aquém das metas inicialmente planejadas. A nota que se segue avalia a trajetória dessas políticas, procurando sublinhar o significado das mudanças de rota e as perspectivas para os próximos anos.

Assim, a seção 2 analisa a evolução do PAA desde sua instituição, ressaltando-se que os recursos orçamentários aplicados no programa caíram continuamente a partir de 2013, o que comprometeu seriamente seus resultados. Diante da persistência do cenário fiscal restritivo, entretanto, a mais recente modalidade do PAA, Compra Institucional, criada em 2012, cresceu significativamente e ocupou parte do espaço esvaziado. Conforme será apresentado, tal modalidade confere, na verdade, autorização a estados, municípios e órgãos federais da administração 
direta e indireta para a compra de alimentos da agricultura familiar com dispensa de licitação. Os recursos financeiros são do próprio órgão adquirente, e, portanto, sua execução prescinde de recursos orçamentários específicos do programa. Na seção 3 , esta nota destaca a relevância das aquisiçôes de alimentos da agricultura familiar realizadas no âmbito do PNAE, mas ressalta que o volume de recursos destinado ainda está aquém do potencial e sua trajetória de crescimento é lenta. Por fim, a seção 4 apresenta algumas consideraçóes finais a respeito do desempenho recente das políticas de compras públicas da produção da agricultura familiar.

\section{PAA: CRESCIMENTO INTERROMPIDO E PERSPECTIVAS}

O PAA atua de forma bastante diversificada, seja por suas diferentes modalidades de ação, por suas fontes de recursos, ou, ainda, pelos agentes que o executam na ponta. Tal diversidade - sintetizada no quadro 1 , a seguir - responde a demandas específicas da política, reconhecidas ao longo de sua trajetória institucional, e a orientações estratégicas relacionadas à sua gestão.

QUADRO 1

Modalidades, fonte de recursos e executores do PAA

\begin{tabular}{|c|c|c|}
\hline Modalidade & Fonte de recursos & Executor \\
\hline Compra com Doação Simultânea & $\begin{array}{l}\text { Secretaria Especial do Desenvolvimento Social/ } \\
\text { Ministério da Cidadania }\end{array}$ & $\begin{array}{l}\text { Companhia Nacional de Abastecimento } \\
\text { (Conab), estados e municípios }\end{array}$ \\
\hline $\begin{array}{l}\text { Incentivo à Produção e } \\
\text { Consumo de Leite (PAA Leite) }\end{array}$ & $\begin{array}{l}\text { Secretaria Especial do Desenvolvimento Social/ } \\
\text { Ministério da Cidadania }\end{array}$ & $\begin{array}{l}\text { Estados da região Nordeste e norte de } \\
\text { Minas Gerais }\end{array}$ \\
\hline Aquisição de Sementes & $\begin{array}{l}\text { Secretaria Especial do Desenvolvimento Social/ } \\
\text { Ministério da Cidadania }\end{array}$ & Conab \\
\hline $\begin{array}{l}\text { Compra Direta da } \\
\text { Agricultura Familiar }\end{array}$ & $\begin{array}{l}\text { Secretaria Especial do Desenvolvimento Social/ Minis- } \\
\text { tério da Cidadania e Secretaria Especial de Agricultura } \\
\text { Familiar e do Desenvolvimento Agrário /Ministério da } \\
\text { Agricultura, Pecuária e Abastecimento (Sead/Mapa) }\end{array}$ & Conab \\
\hline $\begin{array}{l}\text { Apoio à Formação de Estoques } \\
\text { pela Agricultura Familiar }\end{array}$ & Sead/Mapa & Conab \\
\hline Compra Institucional & $\begin{array}{l}\text { Órgãos públicos municipais, estaduais ou federais, } \\
\text { com recursos financeiros próprios }\end{array}$ & $\begin{array}{l}\text { Órgãos públicos municipais, estaduais } \\
\text { ou federais }\end{array}$ \\
\hline
\end{tabular}

Fonte: Secretaria Especial do Desenvolvimento Social/Ministério da Cidadania. Disponível em: <http://twixar.me/5xxK >. Acesso em: 20 mar. 2019.

Elaboração dos autores.

A principal modalidade do programa (Compra com Doação Simultânea, que concentra a maior proporção de agricultores fornecedores) objetiva atender a demandas locais de suplementação alimentar. Os produtos adquiridos dos agricultores familiares são doados às pessoas em situação de insegurança alimentar, por meio de rede socioassistencial ou equipamentos públicos de segurança alimentar e da rede pública e filantrópica de ensino. Para isso, conta com recursos da Secretaria Especial do Desenvolvimento Social do Ministério da Cidadania e é operada por meio de parcerias desse ministério com a Conab - 
via termo de execução descentralizada (TED) -, ou com governos de estados e municípios - por meio de celebração de termo de adesão. ${ }^{5}$

A segunda modalidade com volume expressivo de agricultores participantes é o PAA Leite, que tem o objetivo de aumentar o consumo de leite nas famílias em situação de vulnerabilidade social por meio de sua distribuição gratuita, além de incentivar a produção leiteira pelos agricultores familiares, para fortalecer o setor produtivo local. A modalidade opera com recursos da Secretaria Especial do Desenvolvimento Social do Ministério da Cidadania e tem sua cobertura circunscrita aos estados da região Nordeste e ao norte de Minas Gerais. As famílias beneficiárias do programa podem receber até sete litros de leite por semana, tendo prioridade aquelas com perfil do Bolsa Família e indivíduos atendidos pela rede de assistência social, por equipamentos públicos de alimentação e nutrição.

As três demais modalidades que operam com recursos orçamentários específicos do PAA (Aquisição de Sementes, Compra Direta da Agricultura Familiar e Apoio à Formaçáo de Estoques pela Agricultura Familiar) têm peso relativamente pequeno no programa. A Aquisição de Sementes começou a funcionar em 2015, com recursos da Secretaria Especial do Desenvolvimento Social do Ministério da Cidadania. Seu objetivo é adquirir sementes da agricultura familiar - vedada a aquisição de sementes geneticamente modificadas -, para que estas sejam destinadas a agricultores familiares inscritos no Cadastro Único para Programas Sociais, mulheres, assentados, povos indígenas, quilombolas e demais povos e comunidades tradicionais. A modalidade Compra Direta da Agricultura Familiar - executada com recursos do Ministério da Cidadania e da Sead do Mapa e operacionalizada por meio da Conab - já teve participação mais relevante no programa, mas sua atribuição original (a de ser um instrumento de compra pública) foi alterada em 2014, quando passou a funcionar exclusivamente como política de sustentação de preços, acionável apenas quando os níveis de preço do mercado ficam aquém de certo patamar (Brasil, 2014). Por fim, o Apoio à Formação de Estoques pela Agricultura Familiar consiste em política de apoio financeiro para a constituição de estoques de alimentos por organizaçôes da agricultura familiar, com o objetivo de posterior comercialização e devoluçáo de recursos ao poder público. A operacionalização cabe à Conab, a partir de TED firmado com a Sead.

A última modalidade do quadro 1, Compra Institucional, diferencia-se das demais por prescindir de recursos orçamentários específicos do PAA. Foi instituída em 2012, com a finalidade de autorizar e incentivar estados, o DF e municípios além de órgãos federais - a também comprar alimentos da agricultura familiar,

5. Até 2012, o PAA foi executado pelos estados, pelo Distrito Federal (DF) e pelos municípios, por meio de convênios com 0 antigo Ministério do Desenvolvimento Social e Combate à Fome (MDS) - atual Secretaria Especial do Desenvolvimento Social do Ministério da Cidadania. Com a Lei no 12.512/2011 (Brasil, 2011), regulamentada pelo Decreto ํo 7.775/2012 (Brasil, 2012), abriu-se a possibilidade de execução do PAA mediante a celebração de termo de adesão, dispensada à formalização de convênio. 
com recursos financeiros próprios, dispensando-se a licitação para atendimento às demandas regulares de consumo de alimentos. Podem ser abastecidos hospitais, quartéis, presídios, restaurantes universitários, refeitórios de creches e escolas filantrópicas, entre outros exemplos. Como se argumentará adiante, essa modalidade tem ampliado consideravelmente sua participação no programa. ${ }^{6}$

\subsection{Evolução dos recursos aplicados com orçamento específico do PAA e seus reflexos na política}

A evolução dos recursos aplicados no PAA revela que o programa cresceu continuamente ao longo dos seus primeiros dez anos de operação, mas a partir de então esse crescimento foi interrompido. Em 2013, ano da inflexáo de sua trajetória, uma série de ajustes internos na Conab e uma redefinição do desenho institucional da política executada pelo antigo MDS - atual Secretaria Especial do Desenvolvimento Social do Ministério da Cidadania - foram determinantes para explicar a acentuada queda de desempenho do programa. Foi verificada diminuição de 47,2\% dos recursos investidos nesse ano em relação ao ano anterior e uma baixa de 49,8\% no número total de produtores familiares que participavam como beneficiários fornecedores do programa.

Conforme analisam Galiza e Valadares (2015), as mudanças na Conab objetivavam aperfeiçoar e padronizar os controles administrativos do programa. Ao longo dos dez anos anteriores, seu crescimento ocorreu simultaneamente à construção de aparato legal e burocrático para respaldá-lo. A estrutura operacional para monitorá-lo e fiscalizá-lo foi montada, nesse contexto, em resposta aos desafios e às lacunas despontados, muitas vezes colocados pelos próprios órgãos de controle. Assim, se a forte expansão do PAA Conab teve efeito fundamental para sua consolidaçáa, a iniciativa de repactuar os processos internos para oferecer condiçóes administrativas e legais que sustentassem seu crescimento foi reconhecida pela Conab como igualmente essencial, a despeito das restrições que tal medida acarretou à execução de 2013.

A retomada do crescimento após 2013, entretanto, não ocorreu. A estratégia da Conab foi acompanhada por uma nova diretriz do antigo MDS, principal fonte de recursos e instância normatizadora do programa: privilegiar açóes do PAA executadas diretamente por estados e municípios, eliminando a necessidade de celebrar convênios com esses entes e substituindo tais instrumentos por termos de adesão. A substituição dos convênios por termos de adesão implicou redução significativa dos trâmites burocráticos e da necessidade de acompanhamento e de controle

6. Para uma descrição mais acurada das modalidades do PAA, ver Ipea (2013; 2014). 
das ações realizadas pelos entes federados por parte do ministério. ${ }^{7} \mathrm{O}$ programa redirecionou, assim, sua estratégia, e o papel da Conab nessa nova configuração foi reduzido.

Além disso, o baixo dinamismo da economia a partir de 2014 e o austero regime fiscal implementado a partir de 2015 comprometeram seriamente a recuperação do PAA após o "freio de arrumação" de 2013. Desde então, a evolução do PAA não se restabeleceu. Atualmente, o programa apresenta execução próxima aos primeiros anos de sua instituição, quando o esforço para colocá-lo em operação ainda era o problema central na gestão da política (gráfico 1).

GRÁFICO 1

Evolução dos recursos aplicados pelo PAA (2003-2017)

(Em R\$ milhões)

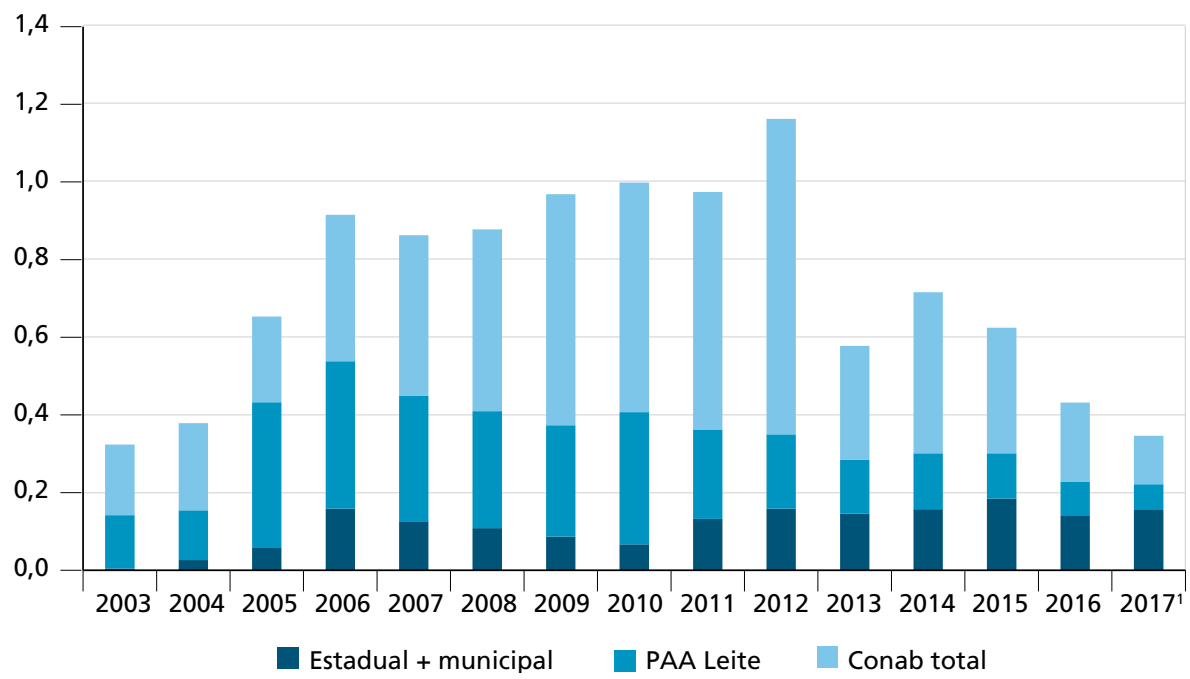

Fonte: Relatório de Fiscalização do Tribunal de Contas da União (TCU), resultados da Conab e do PAA Data. Nota: ${ }^{1}$ Valores em reais de 2017, atualizados pelo Índice de Preços ao Consumidor Amplo (IPCA).

Obs.: Os dados referentes aos anos compreendidos entre 2003 e 2010 do PAA Leite e do PAA estadual + municipal têm como fonte o Relatório de Fiscalização do TCU (2013) e o PAA Conab Total, o relatório de resultados da Conab (Brasil, 2017). A partir de 2011, a fonte de todas as informações é o PAA Data.

Além da significativa redução dos recursos aplicados no programa desde 2013, é possível observar, no gráfico 1 , também, a importante mudança mencionada na forma de execução da política. Em 2012, quando o programa obteve seu melhor desempenho, a Conab respondia por $70 \%$ do total de recursos aplicados no programa, enquanto em 2017 essa participação foi de apenas 36\%. Tal reorientação altera sensivelmente a maneira como a política é operacionalizada. No PAA Conab, as compras públicas são realizadas por meio de propostas de participação de cooperativas 
e associaçôes da agricultura familiar, que os pequenos produtores constituem para viabilizar seu ingresso no programa, não apenas com vistas à ampliação da escala da produção, mas também com efeitos importantes sobre sua auto-organização e a estruturação produtiva dos agricultores. Tais propostas de participação são celebradas entre as cooperativas e associaçóes e a Conab, em consonância com os TEDs. Por sua vez, nos PAAs estadual e municipal, as compras são realizadas por meio de prefeituras e governos estaduais, a partir da seleção de agricultores familiares individuais, que são pagos em cartão magnético diretamente pelo ministério, no caso das operaçôes por intermédio dos termos de adesão.

Em outras palavras, a redução na participação da Conab aponta para a consolidação de um desenho institucional no qual perdem protagonismo as associações de pequenos produtores e suas respectivas redes locais de doação de alimentos, e passam a assumir posição central - como unidades executoras - as instâncias municipais e estaduais de governo. Nesse processo, o governo federal tende cada vez mais a restringir sua atuação à normatização e à execução orçamentária, deixando, aos governos estaduais e municipais aderentes ao programa, a tarefa de articulá-lo na ponta, selecionando os agricultores beneficiários, definindo as unidades recebedoras dos produtos e prestando apoio logístico às entregas. Além disso, é também de responsabilidade dos estados e das prefeituras participantes fazer o registro correto e tempestivo no sistema informatizado de gestão do PAA (SISPAA) de todas as informaçóes necessárias para que o ministério autorize o pagamento aos beneficiários, e é, igualmente, responsabilidade exclusiva das unidades executoras fiscalizar, supervisionar, emitir e guardar toda a documentação fiscal referente à operacionalização do programa. Em outras palavras, o novo desenho operacional não desburocratizou o PAA, apenas aprofundou o processo de descentralização, transferindo para as unidades executoras não somente a responsabilidade pela execução da política, mas também por seu planejamento, sua administração e sua fiscalização.

A evolução dos recursos aplicados no programa por modalidade revela mais detalhes sobre a dinâmica do PAA no período mais recente, quando se deu a inflexão em sua trajetória de crescimento. A tabela 1 mostra que o total de recursos aplicados nesse programa em 2017 ( $\mathrm{R} \$ 346,4$ milhóes) foi 70\% inferior ao de 2012 e 20\% inferior ao de 2016. A redução do total de recursos aplicados nas operaçôes do PAA Conab em 2017 foi de $85 \%$, em relaçâo a 2012, e de 39\%, no que concerne a 2014 . A modalidade Doaçáo Simultânea operada pela Conab - a que responde pela maior quantidade de recursos e pelo maior número de agricultores beneficiados - registrou queda de $82 \%$ de 2012 para 2017 . No quadro global de retração das ações do programa, apenas o PAA municipal teve crescimento: 9\% no período analisado. 
TABELA 1

Evolução dos recursos aplicados no PAA por linha/modalidade (2012-2017) (Em R\$ milhões) ${ }^{1}$

\begin{tabular}{lrrrrrrr}
\hline Linhas/modalidade & 2012 & 2013 & 2014 & 2015 & 2016 & 2017 & $2017-2012(\%)$ \\
\hline PAA Conab & 812,4 & 292,8 & 414,5 & 323,4 & 204,4 & 124,7 & -85 \\
Doação Simultânea & 547,1 & 230,1 & 351,3 & 271,4 & 190,3 & 98,2 & -82 \\
$\begin{array}{l}\text { Apoio à Formação de Estoques pela Agricultura } \\
\text { Familiar }\end{array}$ & 131,7 & 37,3 & 39,0 & 23,4 & 9,9 & 4,9 & -96 \\
Compra Direta da Agricultura Familiar & 133,6 & 25,4 & 24,2 & 12,5 & 0,0 & 16,6 & -88 \\
Aquisição de Sementes & 0,0 & 0,0 & 0,0 & 16,1 & 4,1 & 5,0 & - \\
PAA municipal & 82,6 & 52,4 & 78,5 & 101,3 & 81,6 & $90,1^{2}$ & +9 \\
PAA estadual & 76,6 & 93,2 & 79,0 & 83,8 & 58,1 & $65,2^{2}$ & $-14,8$ \\
PAA Leite & 190,7 & 139,6 & 143,9 & 116,3 & $\mathbf{8 7 , 7}$ & $\mathbf{6 6 , 4}$ & -65 \\
Total & $\mathbf{1 . 1 6 2 , 3}$ & $\mathbf{5 7 8 , 0}$ & $\mathbf{7 1 5 , 9}$ & $\mathbf{6 2 4 , 8}$ & $\mathbf{4 3 1 , 8}$ & $\mathbf{3 4 6 , 4}$ & $-\mathbf{7 0}$ \\
\hline
\end{tabular}

Fontes: Dados da Conab. Relatórios de Execução do PAA (2012 a 2016). Disponível em: <http://twixar.me/NxxK>. Dados dos PAAs municipal, estadual e Leite: PAA Data. Disponivel em <http://twixar.me/CxxK>.

Elaboração dos autores.

Notas: ' Dados deflacionados para valores de 2017 a partir do IPCA anual médio.

${ }^{2}$ Até o fechamento desta nota, a informação disponível sobre o PAA municipal e o PAA estadual era preliminar e agregada. A desagregação da informação no PAA municipal e PAA estadual apresentada na tabela é uma estimativa a partir da participação percentual dessas duas linhas em 2016, quando $58 \%$ dos recursos para estados e municípios foram para as prefeituras e $42 \%$ foram para os governos estaduais.

A retração das ações do PAA Conab - e, em particular, da modalidade Doação Simultânea operada sob essa linha, ainda que venha a ser atenuada em alguma medida pelo crescimento dessa modalidade na linha do PAA municipal - denota mudança importante nos rumos do programa. A Doação Simultânea da Conab atende produtores menos estruturados, para os quais a garantia da compra pública da produção funciona como indutor de organização da atividade produtiva. Se, como apontam os dados, a Conab segue efetivamente perdendo espaço no PAA, essa modalidade - continuada pelas linhas dos PAAs municipal e estadual - envolve regras diferentes de participação que, se tornando predominantes, devem imprimir um desenho diverso ao programa.

Conforme foi dito, para praticarem a Doação Simultânea sob operação pela Conab, os produtores precisam engajar-se em cooperativas ou associaçôes e inscrever uma proposta de participação, definindo as entidades locais (escolas, asilos e creches) em que serão entregues os alimentos; tais condiçóes tenderiam, em tese, a promover a auto-organização dos produtores, gerar uma escala maior de produção e estimular arranjos produtivos locais. Na Doação Simultânea operada por municípios e estados, os produtores podem participar individualmente, entregando sua produção em um centro de distribuição local e recebendo pagamento direto por meio de cartão bancário.

Caso essa linha de operação da Doação Simultânea venha prevalecer no PAA, pode-se supor que, sem a indução à auto-organização, os produtores individuais já mais bem-estruturados devem ampliar sua participação relativa no programa, embora 
seja oportuno reconhecer que o fortalecimento de institucionalidades locais (estados e municípios) na cogestão do PAA também pode ser benéfico para o futuro da política pública de aquisiçôes de alimentos, ainda que sob dependência de recursos federais. De todo modo, esse eventual efeito positivo somente ganhará relevância caso seja revertida a trajetória de redução acentuada das açôes do programa.

Do ponto de vista das fontes dos recursos operados pela Conab, é possível observar duas tendências. Em primeiro lugar, a participação do antigo Ministério do Desenvolvimento Agrário (MDA) - atual Sead - tornou-se praticamente residual no programa: desde 2013, os recursos oriundos do então MDA restringem-se ao financiamento da modalidade Apoio à Formação de Estoques pela Agricultura Familiar. A partir do Decreto n⿳07.775/2012, a modalidade passou a restringir a possibilidade de quitação do apoio financeiro dado aos produtores por meio da destinação da produçáo aos estoques públicos - liquidação física ou entrega dos produtos -, estabelecendo, pois, uma nova prática administrativa, que veio a consolidar-se de fato com a Lei no 8.293/2014 (Brasil, 2014). Reforçando conjectura já considerada em estudo anterior (Galiza e Valadares, 2015), os dados parecem apontar que a definiçâo do pagamento financeiro como forma exclusiva de quitação do Apoio à Formação de Estoques pela Agricultura Familiar afastou da modalidade os produtores rurais, em virtude do receio de que a participação nesta implicasse a contração de uma dívida. ${ }^{8}$

A tabela 2, a seguir, mostra como a queda dos recursos aplicados no PAA repercutiu sobre o número de agricultores que fornecem alimentos. Os dados apontam que, de 2012 a 2017, o total de produtores participantes se reduziu em $64 \%$. No período, todas as linhas e modalidades, à exceção do PAA municipal, experimentaram alguma redução. Em conjunto, o PAA Conab perdeu $85 \%$ do total de agricultores participantes (de 128,8 mil para 18,7 mil) em suas modalidades.

TABELA 2

Número de participantes do PAA por linha/modalidade (2012-2017)

\begin{tabular}{|c|c|c|c|c|c|c|c|}
\hline Linhas/ modalidade & 2012 & 2013 & 2014 & 2015 & 2016 & 2017 & $2017-2012(\%)$ \\
\hline PAA Conab & 128.804 & 41.412 & 51.228 & 38.794 & 29.318 & 18.688 & -85 \\
\hline Doação Simultânea & 95.123 & 33.749 & 43.859 & 33.396 & 27.826 & 15.275 & -84 \\
\hline $\begin{array}{l}\text { Apoio à Formação de } \\
\text { Estoques pela Agricultura } \\
\text { Familiar }\end{array}$ & 11.464 & 4.218 & 4.559 & 2.778 & 1.223 & 676 & -94 \\
\hline $\begin{array}{l}\text { Compra Direta da } \\
\text { Agricultura Familiar }\end{array}$ & 22.217 & 3.445 & 2.810 & 1.559 & 0 & 2.353 & -89 \\
\hline Aquisição de Sementes & 0 & 0 & 0 & 1.061 & 269 & 384 & - \\
\hline
\end{tabular}

(Continua)

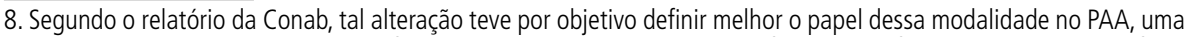
vez que a possibilidade de liquidação física do débito decorrente do apoio financeiro à formação de estoque a fazia funcionar como uma espécie de doação simultânea com pagamento adiantado à entrega. Para mais informações, ver o resultado das ações da Conab em 2013. Disponível em: <http://twixar.me/rxxK>. 


\begin{tabular}{|c|c|c|c|c|c|c|c|}
\hline Linhas/modalidade & 2012 & 2013 & 2014 & 2015 & 2016 & 2017 & 2017- $2012(\%)$ \\
\hline PAA municipal & 17.192 & 14.210 & 18.060 & 19.660 & 19.338 & $21.145^{1}$ & 23 \\
\hline PAA estadual & 18.753 & 21.785 & 22.308 & 17.993 & 14.923 & $16.614^{1}$ & -11 \\
\hline PAA Leite & 28.254 & 20.051 & 22.475 & 19.757 & 13.216 & 12.499 & -56 \\
\hline Total & 193.003 & 97.458 & 114.071 & 96.204 & 76.795 & 68.946 & -64 \\
\hline
\end{tabular}

Fontes: Conab. Disponível em: <http://twixar.me/rDJ1>; Brasil. Disponível em: <http://twixar.me/fFJ1>. Elaboração dos autores.

Nota: ${ }^{1}$ Até o fechamento desta nota, a informação disponível sobre o PAA municipal e o PAA estadual era preliminar e agregada. A desagregação da informação no PAA municipal e no PAA estadual apresentada na tabela é uma estimativa a partir da participação percentual dessas duas linhas em 2016, quando 56\% dos participantes eram do PAA municipal e $44 \%$, do PAA estadual.

Se as linhas operadas pela Conab foram as que assinalaram as mais fortes reduções, a única linha que cresceu e se manteve estável no período foi o PAA municipal, operado sob a modalidade Doação Simultânea: uma alta de 23\% do número de agricultores participantes entre 2012 e 2017. O PAA estadual, em contrapartida, teve redução de $11 \%$ no total de produtores. Aparentemente, tal tendência inversa parece explicar-se pelos processos distintos com que essas linhas realizaram a transição da execução da política via convênio para a execução por meio de termo de adesão, iniciada por volta de $2013 .^{9}$

Conforme o PAA Data, 2013 foi último ano em que o PAA municipal operou por convênio - quando, dos 14,2 mil agricultores dessa linha, 10,7 mil já participavam via termo de adesão -, funcionando exclusivamente por termo de adesão a partir de 2014; por sua vez, no PAA estadual, quase metade dos agricultores estavam vinculados por convênio ao programa em 2014, sem que, no biênio seguinte, quando os convênios caíram a menos de 3\% do total de operaçóes, as participaçôes via termo de adesão compensassem a redução.

Duas hipóteses podem ser aventadas para explicar, ainda que em parte, tal comportamento. Em primeiro lugar, a participação de estados e municípios via termo de adesão transfere a esses entes, como unidades executoras do programa, um conjunto de responsabilidades - atendimento à chamada pública lançada pelo MDS, seleção e cadastramento de fornecedores e entidades que receberão os alimentos, apoio à logística de distribuição, guarda da documentação de compra e doação, entre outras - que envolveria considerável carga de trabalho burocrático sem participaçáo na gestáo dos recursos, uma vez que - nas operaçóes por termo de adesão - a realização do pagamento pelo MDS se dá diretamente ao agricultor, por meio de cartão bancário específico. ${ }^{10}$ Isso pode significar também, em segundo lugar, que governos estaduais, cuja esfera de prioridades tende a ser, em geral, mais distanciada das questóes relativas à agricultura

9. Por efeito da Lei no 12.512/2011, regulamentada pelo Decreto oㅡ 7.775/2012.

10. Nas operações por convênio, os governos estaduais e municipais recebem os recursos federais para compra de alimentos e assumem a responsabilidade pela operacionalização. 
familiar, tenham atuação menos efetiva em um programa voltado a esse público que os governos municipais; sobretudo os de pequenos municípios, mais marcados pela ruralidade e cujas administraçóes seriam, em tese, mais sensíveis às demandas do campo. Além disso, pode-se supor que, com a redução do papel da Conab como operadora do programa, a linha PAA municipal - mais aderente às dinâmicas produtivas locais absorveu em parte a intermediação das operaçóes de Doação Simultânea que já estavam em curso sob execução das associaçóes de produtores.

Outras duas modalidades listadas na tabela 2 merecem esclarecimento à parte, pela ausência de beneficiários em alguns anos: a linha PAA Aquisição de Sementes e a modalidade Compra Direta da Agricultura Familiar. Conforme mencionado, o PAA Aquisição de Sementes não registrou beneficiários em 2013 e 2014, porque somente a partir desse último ano, com o Decreto no 8.293 , foi oficialmente implementado (Brasil, 2014). A Compra Direta da Agricultura Familiar - como já exposto anteriormente também - teve sua atribuição original alterada por esse decreto e passou a funcionar exclusivamente como política de sustentação de preços; mudança que explica parte da redução contínua das operações feitas sob essa modalidade.

A redução dos recursos aplicados pelo PAA no período recente acarretou também perdas significativas na quantidade de alimentos adquiridos. Em 2012, por exemplo, esse programa adquiriu 529 mil toneladas de alimentos. Desde então, o total de alimentos adquiridos caiu para 164,7 mil toneladas, em 2013; 226,1 mil toneladas em 2014; 190,1 mil toneladas em 2015; 134,0 mil toneladas, em 2016; e 128,6 mil toneladas em 2017, o pior resultado do período, $76 \%$ menor que o verificado em 2012. ${ }^{11}$

As reduções em relação ao PAA Leite ${ }^{12}$ foram igualmente expressivas. As tabelas 1 e 2 já apontam para as perdas em termos de recursos aplicados - de R $\$ 190,7$ milhôes, em 2012, para R \$ 66,4 milhôes, em 2017, redução de $65 \%$ - e para a diminuição do número de fornecedores - de 28,3 mil, em 2012, para 12,5 mil, em 2017, baixa de 56\% no período. Os dados referentes à quantidade adquirida seguem a mesma tendência: em 2012, 178,1 milhões de litros de leite foram comprados e distribuídos pelo programa. Em 2017, essa quantidade caiu para 14,7 milhóes de litros, queda de $92 \%$.

Uma vez que a dinâmica de operações do PAA Leite envolve atores políticos e grupos econômicos de maior peso, seja por favorecer a visibilidade dos governos locais

11. Fonte: os dados referentes ao período compreendido entre 2012 e 2016 são do PAA Data. A informação de 2017 é do Relatório de Gestão do Exercício - 2017, da Secretaria Nacional de Segurança Alimentar (Sesan) do MDS (Brasil, 2018, p. 48). 12. O PAA Leite é financiado pelo MDS e operado por convênios com governos estaduais. 0 programa cobre a região Nordeste e municípios do norte de Minas Gerais. Os estados são encarregados de contratar os laticínios que realizam a coleta, a pasteurização, o acondicionamento e o transporte do leite para os pontos de distribuição. Podem participar, como fornecedores, agricultores familiares com capacidade máxima de produção de até 150l/dia, Podem cadastrar-se como beneficiárias as famílias que tenham renda per capita de até meio salário mínimo e, entre seus membros, crianças de 2 a 7 anos, nutrizes ou idosos. 
encarregados da distribuição do leite à população carente, seja por criar incentivos aos grandes laticínios que concentram o beneficiamento do produto, essa linha poderia mostrar-se mais resistente às perdas orçamentárias sofridas pelo programa.

\subsection{Evolução dos recursos aplicados na modalidade Compra Institucional}

O Decreto no 7.775/2012 incluiu a modalidade Compra Institucional no PAA. Sua diferença em relação às demais reside no fato de que, por meio desta, estados, municípios e órgãos federais puderam começar a adquirir alimentos da agricultura familiar com seus próprios recursos financeiros. Hospitais, quartéis, presídios, restaurantes universitários e outras instituiçóes - com demandas regulares de alimentos - tornaram-se beneficiários consumidores dessa modalidade. $\mathrm{O}$ órgão define a demanda e divulga-a em um edital de chamada pública, e os empreendimentos de agricultura familiar - associações e cooperativas, que disponham de Declaração de Aptidão ao Pronaf (DAP) jurídica - submetem suas propostas de venda, com os produtos a preço de mercado, para serem habilitados e passarem a fornecer alimentos à instituição compradora.

Inicialmente, o valor máximo, por unidade familiar, era de $\mathrm{R} \$ 8 \mathrm{mil} / \mathrm{ano}$. A partir do Decreto no 8.293/2014, esse valor foi elevado a $\mathrm{R} \$ 20$ mil, por família, por órgão comprador. Ao mesmo tempo, o valor máximo a ser recebido por cada organização de produtores - respeitado o limite por unidade familiar - foi fixado em $\mathrm{R} \$ 6$ milhóes. O aumento expressivo do limite de participação dos produtores nessa modalidade (de $\mathrm{R} \$ 8 \mathrm{mil}$ a $20 \mathrm{mil} / \mathrm{ano}$ ), em prazo curto, pode ser indício da direção que deve tomar a política de aquisição pública de alimentos e reforça, em princípio, as tendências de desfederalização das operaçóes e de concentração nos segmentos mais estruturados da agricultura familiar.

Segundo o Relatório de Execução-2017 do MDS (Brasil, 2017), que apresentou não somente os resultados da Compra Institucional coordenada por esse ministério, mas também os dos programas estaduais de aquisição de alimentos da agricultura familiar, ${ }^{13}$ o volume de recursos gastos na aquisição de alimentos da agricultura familiar via Compra Institucional aumentou em 7,2 vezes de 2012 a 2017, chegando a $\mathrm{R} \$ 86,7$ milhóes nesse último ano; no biênio 2016-2017, o crescimento dos recursos do PAA Compra Institucional foi da ordem de 52\%. Em relação aos recursos aplicados pelas modalidades operadas com orçamento específico do PAA, os valores do PAA Compra Institucional saltaram de 1\%, em 2012, para 25\%, em 2017.

13. Operados em São Paulo (Programa Paulista da Agricultura de Interesse Social), no DF (Programa de Aquisição da Produção da Agricultura), no Rio Grande do Sul (Compra Pública), em Minas Gerais (Política Estadual de Aquisiçãa de Alimentos da Agricultura Familiar) e em outros estados. 


\section{TABELA 3}

Evolução dos recursos aplicados no PAA pela modalidade Compra Institucional e dos recursos aplicados com orçamento específico do PAA (2012-2017)

\begin{tabular}{lrrrrrrc}
\hline PAA por tipo de recurso & 2012 & 2013 & 2014 & 2015 & 2016 & 2017 & $2017-2012(\%)$ \\
\hline PAA Compra Institucional (A) (R\$ milhões) & 12,0 & 30,4 & 43,8 & 50,5 & 57,1 & 86,7 & 620 \\
$\begin{array}{l}\text { PAA - recursos orçamentários específicos (B) } \\
\text { (R\$ milhões) }\end{array}$ & $1.162,3$ & 578,0 & 715,9 & 624,8 & 431,8 & 346,4 & -70 \\
A/B (\%) & 1 & 5 & 6 & 8 & 13 & 25 & - \\
\hline
\end{tabular}

Fonte: Relatório de Execução - 2017, PAA modalidade Compra Institucional 2017 (Brasil, 2017).

Elaboração dos autores.

Nota: ${ }^{1}$ Dados deflacionados para valores de 2017, a partir do IPCA anual médio.

O retrato dos órgãos executores - que desembolsam recursos próprios para aquisição de alimentos - da Compra Institucional ilustra não apenas a destinação que a produção agrícola familiar vem tendo no âmbito dos órgãos federais - e de suas representaçôes em UFs e municípios, em quartéis, escolas e hospitais -, mas, especialmente, o peso significativo das compras realizadas pelos estados. Com efeito, em 2016, o então MDS respondeu por 33,7\% do total das compras, seguido pelo Ministério da Defesa (MD), com 28,4\%, pelo Ministério da Educação (MEC), com 17,29\%, e pelo Ministério da Saúde (MS), com 4,1\%; o governo de São Paulo, porém, arcou com $14,8 \%$ do total dos recursos gastos na modalidade.

O quadro de 2017 é ligeiramente diverso, com acentuação da contribuição dos estados na execução orçamentária: o MD aplicou 28,3\% dos recursos, seguido pelo MDS, com $16,4 \%$, e pelo MEC, com pouco mais de $1 \%$. No entanto, os governos de Alagoas, com 24\%, de Sáo Paulo, com 14,4\%, e do DF, com 9,7\%, responderam, juntos, por praticamente metade do total gasto. A confirmar-se nos exercícios posteriores, essa tendência à descentralização na execução da Compra Institucional com a criação de órgãos e legislação própria em nível estadual, pode tornar-se um vetor essencial da continuidade do programa em um contexto de crise econômica e de perda de institucionalidade das políticas de desenvolvimento rural na esfera federal.

O último biênio registrou também aumento no número de empreendimentos da agricultura familiar como beneficiários fornecedores da modalidade: ${ }^{14} \mathrm{em}$ 2016, 79 empreendimentos (cooperativas e associações) ${ }^{15}$ da agricultura familiar comercializaram seus produtos pela modalidade Compra Institucional; em 2017, esse número se elevou a $129 .{ }^{16}$ No entanto, a oferta parece ainda bastante concentrada nos estados da região Sul: de 2012 a 2015, Paraná, Santa Catarina e

14. De 2012 a 2015, 102 empreendimentos da agricultura familiar foram beneficiários fornecedores do programa. Até o fechamento da redação deste texto, não foi possível obter a informação desagregada por ano para esse período. Para mais informações, ver Brasil (2016b).

15. Para mais informações, ver Brasil (2016a).

16. Para mais informações, ver Brasil (2017, p. 18). 
Rio Grande do Sul - sempre com maior peso sobre este último - responderam por $48 \%$ do total de empreendimentos de agricultura familiar participantes do PAA Compra Institucional; em 2016, eram 52\%; em 2017, 36\%. Esse perfil de oferta, com predomínio dos estados sulistas, sugere que o setor da agricultura familiar mais estruturada tem sido o principal beneficiário da Compra Institucional. Tal tendência emula, de certo modo, a trajetória do PAA Conab até 2010, quando a maior parte dos recursos era destinada aos estados do Sul, com maior peso relativo das modalidades de Compra Direta da Agricultura Familiar e Apoio à Formação de Estoques pela Agricultura Familiar, em geral acessadas pela agricultura familiar mais dinâmica economicamente.

Sem dúvida, é importante que a modalidade Compra Institucional seja fortalecida como política pública de aquisição de alimentos que propicia, à agricultura familiar mais consolidada, alternativa de comercializaçáo da produção capaz de garantir a esse setor maior segurança econômica e de protegê-lo contra as oscilaçóes de mercado. O que parece pouco provável, dado o perfil da oferta do PAA Compra Institucional, é que este seja capaz de absorver os pequenos produtores - mais empobrecidos, concentrados na regiáo Nordeste do país -, que vêm perdendo espaço no programa em virtude do encolhimento da modalidade Doação Simultânea do PAA Conab. Vale lembrar, a título de comparação, que essa modalidade opera com valores significativamente inferiores aos limites da Compra Institucional: $\mathrm{R} \$$ 6,5 mil por família/ano, $\mathrm{R} \$ 2$ milhóes por organização/ano.

\section{PROGRAMA NACIONAL DE ALIMENTAÇÃO ESCOLAR}

Ao estabelecer as diretrizes para a garantia do direito à educação, a Constituiçáo Federal prevê, no inciso VII do art. 208, a obrigação de o Estado prover uma série de medidas suplementares de atendimento ao estudante do ensino básico público, com vistas a lhe fornecer alimentação, material didático, transporte e assistência à saúde. O PNAE é uma dessas medidas, configurando a política pública que operacionaliza o repasse de recursos federais para a alimentação escolar.

O PNAE é regido pela Lei oㅗ11.947/2009 (Brasil, 2009). Tem por objetivo oferecer ações de educação alimentar e nutricional e fornecer refeiçôes que supram as necessidades nutricionais dos alunos da educação básica, a fim de auxiliar no desenvolvimento da aprendizagem, no rendimento escolar e na formação de hábitos alimentares saudáveis (art. $4^{\circ}$ da lei). O programa estabelece um arranjo institucional entre Uniáo, estados e municípios, pelo qual a primeira repassa recursos federais do FNDE para os demais adquirirem produtos alimentícios para as escolas.

A alimentação escolar deve atender a uma série de princípios que se referem à alimentação saudável e adequada, à segurança alimentar e nutricional, ao respeito à cultura e aos hábitos alimentares locais, bem como à priorização de gêneros alimentícios 
produzidos localmente, advindos da agricultura familiar. A fim de possibilitar a participação da agricultura familiar no processo de obtenção de alimentos, a lei estabelece que ao menos 30\% dos recursos repassados pelo FNDE para a alimentação escolar devem ser destinados para aquisição de gêneros alimentícios produzidos por agricultores familiares, com prioridade para comunidades tradicionais e assentamentos da reforma agrária (Brasil, 2009). Cria-se, desse modo, marco institucional voltado para a geração de círculo virtuoso entre produção e consumo locais de alimentos, o que permite, no lado da produção, o acesso da agricultura familiar a um importante canal de comercializaçáo com promissores incrementos da renda local e, no lado do consumo, o acesso de crianças e jovens à alimentação saudável, nutritiva e diversificada.

As aquisiçóes de alimentos da agricultura familiar, no âmbito do PNAE, são feitas pelas denominadas entidades executoras: secretarias estaduais de educação, municípios e escolas federais, que podem descentralizar a aquisição para as organizaçóes sem fins lucrativos, que representam a comunidade escolar, chamadas de unidades executoras. Podem se habilitar como fornecedores aqueles agricultores com DAP emitida pelo governo federal. A participação pode ser individual ou coletiva, por meio de associaçóes ou cooperativas. O processo de compra é efetuado com dispensa de licitação, bastando a realização de chamada pública de projetos de fornecimento. A seleção dos projetos deve seguir a diretriz de priorização de circuitos curtos de produção. Dessa forma, avaliam-se primeiramente os projetos oriundos do município em que a unidade executora está sediada, podendo-se em seguida avaliar projetos de âmbitos territorial, estadual e nacional, nessa ordem.

A concepção da aquisição de alimentos da agricultura familiar, no âmbito do PNAE, para a alimentação escolar configura cenários importantes para o desenvolvimento desse segmento no Brasil, com potencial de dinamização de economias locais e de incremento de renda de pequenos produtores, sobretudo em regiôes predominantemente rurais. No entanto, com base nos dados de implementação do programa em municípios e estados entre 2011 e 2016, ${ }^{17}$ a aquisição de alimentos oriundos da agricultura familiar vem apresentando evolução lenta. Em termos gerais, no primeiro ano da série, o volume de recursos destinados à compra de alimentos oriundos da agricultura familiar foi de $8 \%$ do total realizado pelo PNAE. No último exercício, a proporção ficou em $22 \%$; portanto abaixo do mínimo estipulado pela lei.

17. Os dados utilizados para a análise foram extraídos do portal do FNDE, no site disponível em: <http://twixar.me/ MRhn>. No momento da análise, estavam disponibilizadas informações referentes aos exercícios de 2011 a 2016 , atualizados até 12 de abril de 2018. 
GRÁFICO 2

Recursos gerais do PNAE para aquisição da agricultura familiar (2011-2016) (Em \%)

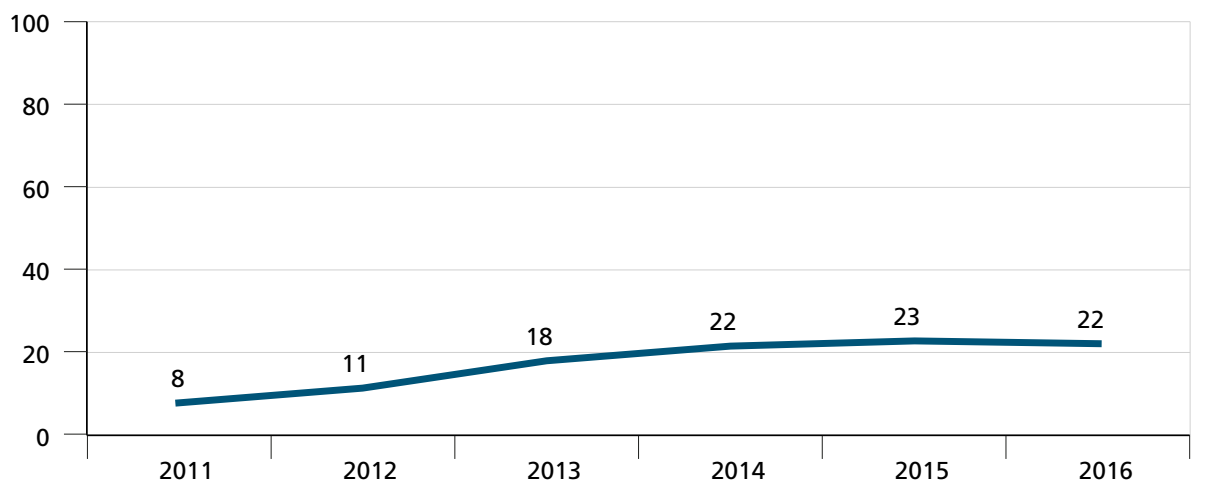

Fonte: FNDE. Disponível em: <http://twixar.me/MRhn>.

Atendo-se ao exercício de 2016, e desagregando-se a execução geral do PNAE por grandes regiôes, a região Sul é a única que consegue cumprir o mínimo legal, utilizando 33\% dos recursos do programa para aquisição de alimentos da agricultura familiar. As regiōes Sudeste e Centro-Oeste apresentaram os menores percentuais: $18 \%$ e $19 \%$, respectivamente.

TABELA 4

Repasse do PNAE para estados e municípios - Grandes Regiões (2016)

\begin{tabular}{lccc}
\hline Rótulos de linha & $\begin{array}{c}\text { Valor transferido do FNDE } \\
(\mathrm{R} \$)\end{array}$ & $\begin{array}{c}\text { Aquisições da agricultura } \\
\text { familiar (R\$) }\end{array}$ & $\begin{array}{c}\text { Agricultura } \\
\text { familiar (\%) }\end{array}$ \\
\hline Centro-Oeste & $295.491 .778,46$ & $57.125 .149,16$ & 19 \\
Nordeste & $1.208 .260 .370,08$ & $266.876 .545,06$ & 22 \\
Norte & $412.162 .629,94$ & $106.681 .886,64$ & 26 \\
Sudeste & $1.463 .116 .780,66$ & $263.543 .037,12$ & 18 \\
Sul & $503.641 .725,17$ & $164.550 .521,57$ & 33 \\
Total geral & $\mathbf{3 . 8 8 2 . 6 7 3 . 2 8 4 , 3 1}$ & $\mathbf{8 5 8 . 7 7 7 . 1 3 9 , 5 5}$ & $\mathbf{2 2}$ \\
\hline
\end{tabular}

Fonte: FNDE. Disponível em: <http://twixar.me/MRhn>.

Ao direcionar a análise para atuação por tipo de entidade executora, nota-se que, do total de recursos repassados pela União no âmbito do PNAE, os municípios detêm em torno de $70 \%$ e as Unidades da Federação (UFs) ficam com cerca de $30 \%$, o que se deve ao maior contingente de estudantes atendidos pela rede municipal de ensino. Em geral, os municípios tendem a aplicar maior percentual do que recebem para a agricultura familiar (em torno de $20 \%$ ), enquanto os estados aplicam $12 \%$ no total de série histórica. Vê-se pouca evolução no número de UFs 
que conseguiram cumprir ou ultrapassar o mínimo legal. Nos dois primeiros anos da série, nenhum estado cumpriu o piso de destinação de recursos para aquisição da agricultura familiar. Nos demais exercícios, houve pequena oscilação, que nunca passou de quatro estados. Em 2016, somente Acre, Amazonas, Ceará e Roraima destinaram ao menos $30 \%$ dos recursos do PNAE para a agricultura familiar. Entre os municípios, mais da metade ainda não havia cumprido o mínimo legal, apesar de se ter evoluído de patamar de 27\%, em 2011, para 45\%, em 2016, em relação à proporção de municípios que cumpriram a cota mínima. Dos 2.331 municípios que cumpriram o mínimo legal em 2016, quase $90 \%$ estão localizados nas regióes Sul, Sudeste e Nordeste.

GRÁFICO 3

Repasse do FNDE, total e destinado à agricultura familiar, por tipo de entidade executora (2016)

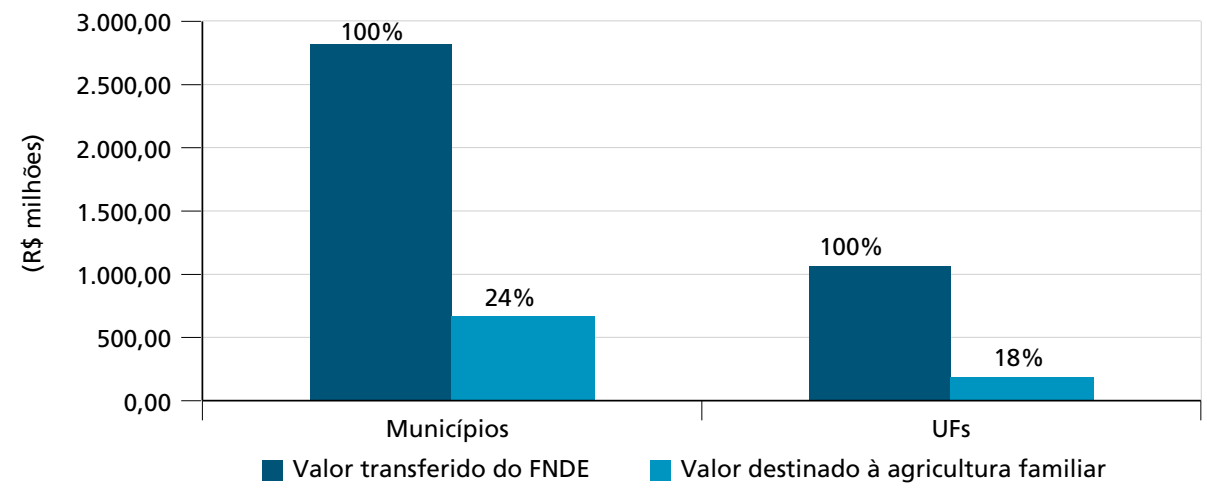

Fonte: FNDE. Disponível em: <http://twixar.me/MRhn>.

Em 2011, cerca de dois quintos dos municípios não utilizaram qualquer recurso do PNAE para aquisição de alimentos produzidos por agricultores familiares. Essa proporção vem decrescendo durante o período considerado, apresentando percentual de $15 \%$ no exercício de 2016 . Por sua vez, a proporção de municípios que executaram todo o recurso do programa para agricultura familiar é bastante baixa, mantendo-se na faixa de $1 \%$ durante os últimos quatro anos. A região Sul é a que concentra a maior parte desses municípios: 36 , em total de 59. Também é a região que apresenta o menor percentual de municípios que não adquiriram qualquer produto da agricultura familiar em 2016. Nesse quesito, as regióes Sudeste e Nordeste apresentaram os maiores índices: $40 \%$ e 33\%, respectivamente. 
GRÁFICO 4

Proporção de municípios e UFs que cumpriu o mínimo legal para aquisição de alimentos da agricultura familiar no âmbito do PNAE (2011-2016)

(Em \%)

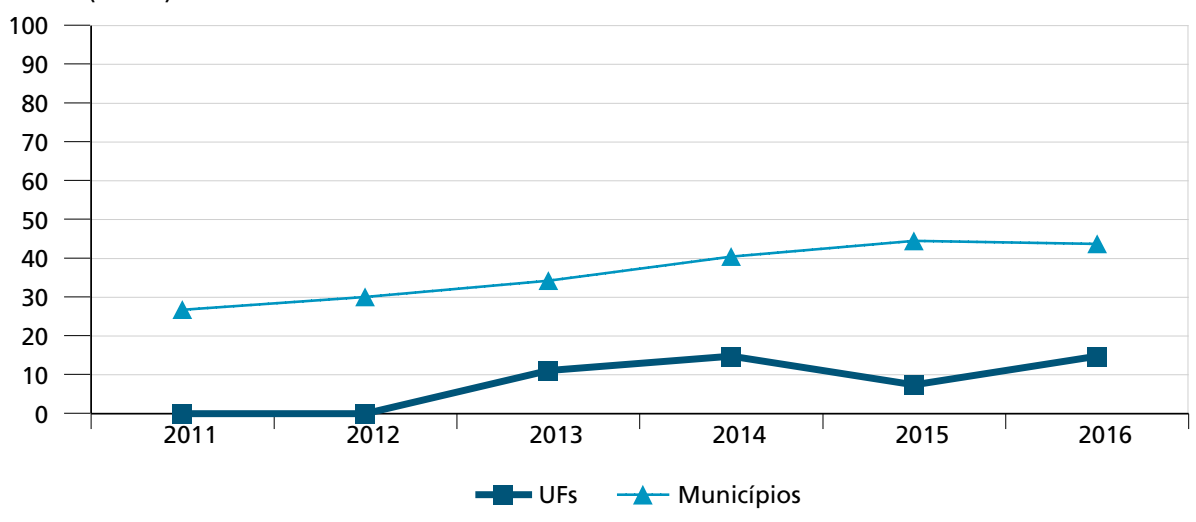

Fonte: FNDE. Disponível em: <http://twixar.me/MRhn>.

Em 2016, foram assinados, em todo o Brasil, 40.485 contratos de fornecimento de alimentos pela agricultura familiar às escolas. Destes, pouco mais de 35 mil foram contratos individuais ou em grupos informais. Os restantes foram realizados com associaçôes ou cooperativas de agricultores. $\mathrm{O}$ valor médio nacional dos contratos individuais foi de $\mathrm{R} \$ 6.647,33$, variando de $\mathrm{R} \$ 4.466,59$, no Rio Grande do Sul, a R\$ 10.247,33, no Amazonas. Com relação aos contratos efetuados mediante associaçóes e cooperativas, o valor médio nacional foi de $\mathrm{R} \$ 122.905,22$, com variação de R \$ 52.389,16, na Paraíba, a R \$ 1,4 milhão, em Roraima, estado que apresenta média muito elevada no que concerne aos demais, cujos valores médios não ultrapassaram a cifra de $\mathrm{R} \$ 450 \mathrm{mil}$.

A fim de estimar o quantitativo de produtores atendidos pelo PNAE, dividiu-se o valor de cada contrato firmado com associaçáo ou cooperativa pelo valor médio dos contratos individuais da respectiva UF. ${ }^{18}$ Dessa forma, chegou-se ao número presumido de 88.574 produtores que forneceram alimentos para o programa por meio de suas associaçóes ou cooperativas. Somado ao número de contratos individuais, tem-se estimativa de 123.987 agricultores familiares que comercializaram alimentos no âmbito do PNAE em 2016. Considerando-se que a destinação dos recursos do programa em todo o Brasil para a agricultura familiar nesse ano ficou na faixa dos $20 \%$ e que não há limite máximo para compra de alimentos oriundos desse segmento da agricultura, os recursos repassados pelo FNDE para a alimentação escolar apresentam potencial de beneficiar um número cinco vezes maior ao que foi efetivamente cumprido, caso fossem utilizados integralmente em compras da agricultura familiar. 
TABELA 5

Agricultores familiares fornecedores de alimentos no âmbito do PNAE (2016)

\begin{tabular}{lccc}
\hline \multirow{2}{*}{ Região } & \multicolumn{3}{c}{ Agricultores familiares fornecedores } \\
\cline { 2 - 4 } & Associações e cooperativas & Contratos individuais & Total \\
\hline Centro-Oeste & 5.109 & 2.296 & 7.405 \\
Norte & 9.105 & 3.238 & 12.343 \\
Nordeste & 22.834 & 12.068 & 34.902 \\
Sul & 24.896 & 8.127 & 33.023 \\
Sudeste & 26.630 & 9.684 & 36.314 \\
Total & 88.574 & 35.413 & 123.987 \\
\hline
\end{tabular}

Fonte: FNDE. Disponível em: <http://twixar.me/MRhn>.

A integração da agricultura familiar na rede de fornecimento de alimentação escolar ainda não foi consolidada, apesar de transcorridos sete anos do marco legal que estabelece um piso dos recursos do PNAE para esse segmento. A despeito da obrigatoriedade da utilização de pelo menos $30 \%$ dos recursos do PNAE para adquirir produtos da agricultura familiar, o cumprimento dessa normativa evolui lentamente. A maior parte dos estados e municípios permanece sem cumprir o mínimo legal. A agricultura familiar representa $85 \%$ dos estabelecimentos agropecuários. É responsável por grande parte dos alimentos que chegam à mesa do cidadão brasileiro. Produz $70 \%$ do feijão, $87 \%$ da mandioca e $58 \%$ do leite. Responde por $58 \%$ dos efetivos de suínos e por $50 \%$ das aves. ${ }^{19}$ Não há, a princípio, problema de oferta. É necessário identificar e resolver os gargalos relacionados aos arranjos institucionais, aos processos de aquisição de alimentos e à própria estruturação dos agricultores, a fim de propiciar a expansão dessa importante política.

Por fim, cumpre frisar que a merenda escolar desempenha papel fundamental na segurança alimentar e nutricional de crianças e adolescentes, que, por vezes, têm, na alimentação recebida na escola, sua principal refeição diária. A participação da agricultura familiar no PNAE amplia o acesso desse público a uma alimentação menos processada e mais saudável.

\section{CONSIDERAÇÕES FINAIS}

Como mostram os dados deste estudo, as políticas de compras públicas da agricultura familiar experimentaram, nos últimos anos, estagnação com viés de declínio; mais acentuada no caso do PAA, mais tênue no caso do PNAE.

No caso desse último programa, pode-se evocar a redução, a partir de 2012, do total de estudantes atendidos pela rede pública como reflexo de um movimento demográfico, mas os dados das compras dos produtos da agricultura familiar

19. Informações disponíveis em: <http://twixar.me/S251>. 
apontam que, no último biênio, se reduziu tanto a proporção de municípios que adquirem - em qualquer quantidade - alimentos dos agricultores familiares (de $83 \%$, em 2015, para $81 \%$, em 2016) quanto a proporção dos municípios que adquirem essa produçáo respeitando a cota de 30\% (de 44\%, em 2015, para $42 \%$, em 2016). A reiteraçáo dessa tendência nos anos seguintes pode ser tomada como indicativo inquietante para o futuro das compras de produtos da agricultura familiar no âmbito do programa.

Outra preocupação oportuna diz respeito à dificuldade que a grande maioria dos municípios tem ao cumprir a cota de 30\%. As informaçóes analisadas revelam que a agricultura familiar mais estruturada empresarialmente - geograficamente localizada na regiấo Sul do país e, na maioria das vezes, organizada em associaçóes ou cooperativas - tem acesso privilegiado ao programa. Por sua vez, os agricultores familiares mais empobrecidos, que representam a maioria dos agricultores familiares, não conseguem participar.

Esse é justamente o processo que aparentemente tem ocorrido no PAA. Com a redução da participação da Conab na política, diminui-se também seu papel de articular e incentivar os agricultores familiares a organizarem-se e fortalecerem-se para integrar as políticas de compras públicas. Se, de fato, a execução do PAA Conab envolve complicaçóes logísticas e burocráticas que acabam por absorver excessivamente a gestão federal do programa, é preciso ter em conta, contudo, que a Doação Simultânea operada pela Conab se revelou, ao longo dos anos recentes, instrumento eficaz de estruturação produtiva de pequenos agricultores. Organizados em associações a partir da perspectiva de compra da produção, os beneficiários dessa modalidade contribuíram significativamente para ampliar em nível local a oferta de alimentos.

Assim, tanto a redução do volume de recursos quanto a do total de fornecedores beneficiários do programa, sobretudo na modalidade Doação Simultânea - que assiste o maior número deles e os grupos mais vulneráveis da agricultura familiar -, deve ser encarada com preocupação. Não se desconsidera a relevância das demais modalidades do PAA; em especial, a Compra Institucional, que atende majoritariamente à agricultura familiar mais economicamente estruturada. Mas seria desejável que o PAA, considerado em seu conjunto, se consolidasse em todas as suas modalidades, atendendo aos variados perfis produtivos da agricultura familiar. Antes disso e urgentemente, seria essencial que o programa voltasse a crescer em recursos e número de beneficiários. 


\section{REFERÊNCIAS}

BRASIL. Lei no 10.696, de 2 de julho de 2003. Dispóe sobre a repactuação e o alongamento de dívidas oriundas de operações de crédito rural, e dá outras previdências. Diário Oficial, Brasília, 3 jul. 2003.

. Lei $\mathrm{n}^{\mathrm{o}} 11.947$, de 16 de junho de 2009. Dispóe sobre o atendimento da alimentação escolar e do Programa Dinheiro Direto na Escola aos alunos da educação básica; altera as leis nos 10.880, de 9 de junho de 2004, 11.273, de 6 de fevereiro de 2006, 11.507, de 20 de julho de 2007; revoga dispositivos da Medida Provisória no 2.178-36, de 24 de agosto de 2001, e a Lei no 8.913, de 12 de julho de 1994; e dá outras providências. Diário Oficial, Brasília, 17 jun. 2009.

. Lei no 12.512 , de 14 de outubro de 2011. Institui o Programa de Apoio à Conservaçáo Ambiental e o Programa de Fomento às Atividades Produtivas Rurais; altera as leis nos 10.696 , de 2 de julho de 2003, 10.836, de 9 de janeiro de 2004, e 11.326, de 24 de julho de 2006. Diário Oficial, Brasília, 17 out. 2011.

. Decreto no 7.775, de 4 de julho de 2012. Regulamenta o art. 19 da Lei no 10.696, de 2 de julho de 2003, que institui o Programa de Aquisição de Alimentos, e o Capítulo III da Lei no 12.512, de 14 de outubro de 2011, e dá outras providências. Diário Oficial, 5 jul. 2012.

. Decreto no 8.293, de 12 de agosto de 2014. Altera o Decreto no 7.775, de 4 de julho de 2012, que dispóe sobre o Programa de Aquisição de Alimentos. Diário Oficial, Brasília, 13 ago. 2014.

. Ministério do Desenvolvimento Social. Programa de Aquisição de Alimentos: modalidade Compra Institucional. Relatório de Execução - 2016. Brasília: MDS, 2016a. Disponível em: <http://twixar.me/v6xK>.

. Ministério do Desenvolvimento Social. Compras da agricultura familiar órgáos públicos: modalidade Compra Institucional do PAA (2012-2015). Brasília: MDS, jul. 2016b. Disponível em: <http://twixar.me/p251>.

- Ministério do Desenvolvimento Social. Programa de Aquisição de Alimentos: modalidade Compra Institucional. Relatório de Execução - 2017. Brasília: MDS, 2017. Disponível em: <http://twixar.me/w6xK>.

Relatório de gestáo do exercício de 2017. Brasília: Ministério do Desenvolvimento Social/Secretaria Nacional de Segurança Alimentar e Nutricional, 2018. Disponível em: <http://twixar.me/yDJ1>.

GALIZA, M.; VALADARES, A. A trajetória recente do Programa de Aquisiçáo de Alimentos da Agricultura Familiar (PAA): uma análise das mudanças normativas e institucionais que deram nova inflexão ao programa. Brasília: Ipea, 2015. (Nota Técnica, n. 21). 
IPEA - INSTITUTO DE PESQUISA ECONÔMICA APLICADA. Políticas sociais: acompanhamento e análise. Brasília, n. 21, cap. 7, 2013.

. Políticas sociais: acompanhamento e análise. Brasília, n. 22, cap. 7, 2014. TCU - TRIBUNAL DE CONTAS DA UNIÁO. Relatório de Fiscalizaçáo TC no 010.395/2013-0. Brasília: TCU, 2013. 